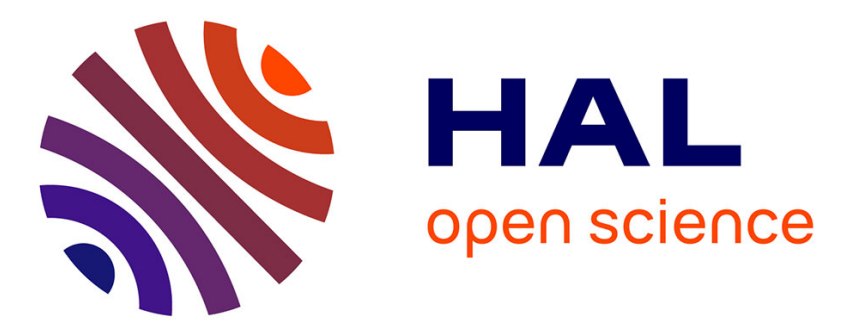

\title{
A Game-Theory Analysis of Electric Vehicle Adoption in Beijing under License Plate Control Policy
}

\author{
Lijing Zhu, Jingzhou Wang, Arash Farnoosh, Xunzhang Pan
}

\section{To cite this version:}

Lijing Zhu, Jingzhou Wang, Arash Farnoosh, Xunzhang Pan. A Game-Theory Analysis of Electric Vehicle Adoption in Beijing under License Plate Control Policy: Les Cahier de l'Economie, Série Recherche, $\mathrm{n}^{\circ} 145$. 2021. hal-03500766

\section{HAL Id: hal-03500766 https://hal-ifp.archives-ouvertes.fr/hal-03500766}

Preprint submitted on 23 Dec 2021

HAL is a multi-disciplinary open access archive for the deposit and dissemination of scientific research documents, whether they are published or not. The documents may come from teaching and research institutions in France or abroad, or from public or private research centers.
L'archive ouverte pluridisciplinaire HAL, est destinée au dépôt et à la diffusion de documents scientifiques de niveau recherche, publiés ou non, émanant des établissements d'enseignement et de recherche français ou étrangers, des laboratoires publics ou privés. 
La collection "Les Cahiers de l'Économie" a pour objectif de présenter les travaux réalisés à IFP Energies nouvelles et IFP School qui traitent d'économie, de finance ou de gestion de la transition énergétique. La forme et le fond peuvent encore être provisoires, notamment pour susciter des échanges de points de vue sur les sujets abordés. Les opinions exprimées dans cette collection appartiennent à leurs auteurs et ne reflètent pas nécessairement le point de vue d'IFP Energies nouvelles ou d'IFP School. Ni ces institutions ni les auteurs n'acceptent une quelconque responsabilité pour les pertes ou dommages éventuellement subis suite à l'utilisation ou à la confiance accordée au contenu de ces publications.

Pour toute information sur le contenu, contacter directement l'auteur.

The collection "Les Cahiers de l'Économie" aims to present work carried out at IFP Energies nouvelles and IFP School dealing with economics, finance or energy transition management. The form and content may still be provisional, in particular to encourage an exchange of views on the subjects covered. The opinions expressed in this collection are those of the authors and do not necessarily reflect the views of IFP Energies nouvelles or IFP School. Neither these institutions nor the authors accept any liability for loss or damage incurred as a result of the use of or reliance on the content of these publications.

For any information on the content, please contact the author directly.

\title{
Pour toute information complémentaire For any additional information
}

\author{
Victor Court \\ IFP School \\ Centre Economie et Management de l'Energie \\ Energy Economics and Management Center \\ victor.court@ifpen.fr \\ Tél +33147527317
}




\title{
A Game-theory Analysis of Electric Vehicle Adoption in Beijing under License Plate Control Policy
}

\author{
Lijing Zhu ${ }^{1}$, Jingzhou Wang ${ }^{1,2}$, Arash FARNOOSH ${ }^{2}$, Xunzhang Pan ${ }^{1}$ \\ ${ }^{1}$ School of Economics and Management, China University of Petroleum, 18 Fuxue Rd, Changping District, Beijing, China \\ 2 IFP Energies nouvelles (IFPEN), IFP School, 232 Avenue Napoléon Bonaparte, 92852 Rueil-Malmaison, France
}

\section{ABSTRACT}

To reduce traffic congestion and protect the environment, license plate control (LPC) policy has been implemented in Beijing since 2011. In 2019, 100,000 vehicle license plates were distributed, including 60,000 for electric vehicle (EV) and 40,000 for gasoline vehicle (GV). However, whether the current license plate allocation is optimal from a social welfare maximization perspective remains unclear. This paper proposes a two-level Stackelberg game which portrays the interaction between vehicle applicants and the government to quantify the optimal EV license plates under the LPC policy in Beijing. The equilibrium number of EV license plates derived from the Stackelberg model is 58,800 , which could increase the social welfare by $0.38 \%$. Sensitivity analysis is conducted to illustrate the impact of important influential factors - total license plate quota, vehicle rental fee, and energy price - on EV adoption. The LPC policy under COVID-19 is also studied through a scenario analysis. If the government additionally increases the total quota by $20,000,24 \%$ could be allocated to GV and $76 \%$ to EV. One third reduction of the current vehicle rental fee could increase EV license plates by $10.5 \%$. In terms of energy prices, when gasoline price is low, reducing electricity price could contribute to EV adoption significantly, while that effect tapers off as the gasoline price rises.

Keywords: Electric vehicle, License plate control (LPC) policy, Stackelberg game theory, License plate quota 


\section{Abbreviation}

\begin{tabular}{|c|c|}
\hline LPC policy & license plate control policy \\
\hline$E V \& G V$ & electric vehicle $\&$ gasoline vehicle \\
\hline$P_{G}$ & average sale price of gasoline vehicles \\
\hline$P_{E}$ & average sale price of electric vehicles \\
\hline$I_{G}$ & gas stations quantity in Beijing \\
\hline$I_{E}$ & charging piles quantity in Beijing \\
\hline$M_{G}$ & Probability of undergoing tail number restriction \\
\hline$N_{G}$ & license plates quantity of gasoline vehicles \\
\hline$B_{G}$ & number of gasoline vehicle applicants \\
\hline$B_{E}$ & number of electric vehicle applicants \\
\hline$K$ & total license plates quota \\
\hline$P_{G V}$ & probability of purchasing gasoline vehicle \\
\hline$P_{E V}$ & probability of purchasing electric vehicle \\
\hline$\varepsilon_{G}$ & $\begin{array}{l}\text { applicant's random preference for gasoline vehicles, uniformly } \\
\text { distributed with } \varepsilon_{G} \sim \mathrm{u}(0,1)\end{array}$ \\
\hline$\varepsilon_{E}$ & $\begin{array}{l}\text { applicant's random preference for electric vehicles, uniformly distributed } \\
\text { with } \varepsilon_{E}=1-\varepsilon_{G}\end{array}$ \\
\hline$\eta$ & market share of gasoline vehicle \\
\hline$U_{G v}$ & utility of gasoline vehicle applicant \\
\hline$U_{E v}$ & utility of electric vehicle applicant \\
\hline$T_{G}$ & waiting time of obtaining a GV license plate in lottery system \\
\hline$T_{E}$ & waiting time of obtaining an EV license plate in queueing system \\
\hline$c$ & rental fee (CNY per month) \\
\hline$D V K T$ & daily vehicle kilometers travelled \\
\hline$p$ & winning probability \\
\hline$P_{g}$ & gasoline price \\
\hline$P_{e}$ & electricity price \\
\hline
\end{tabular}




\section{Introduction}

Nowadays, many cities in China are suffering from deteriorating traffic congestion and air pollution [1][2]. EV promotion has been considered as a promising route to solve such problems. Beijing, as the capital of China, has implemented plenty of policies to improve EV penetration [3], including supplybased policies [4][5] and demand-based policies [6]. Theoretically, supply-based polices are imposed on stakeholders related to EV industry, such as EVs manufacturers and EV charging infrastructures (EVCIs) producers, while demand-based regulations tend to stimulate consumers' willingness to pay for EVs. Demand-based policies can be further classified as economic and non-economic policies by considering the benefits that they offer.

Certain economic incentives have been carried out by Beijing government, such as GV purchasing tax increment in 2004, public transportation fare reduction in 2007, subsidies for EVs and infrastructures since 2011, and EV purchasing tax exemption in 2014. There is no doubt that in the short term, the economic incentives are able to increase EV competitiveness more or less. However, these incentives mainly aim to promote EV adoption but cannot effectively limit vehicle quantity. In other words, economic incentives alone are insufficient to mitigate traffic congestion in Chinese metropolis such as Beijing, Shanghai, and Guangzhou. Worse still, the economic incentives would increase financial burden of the government in the long run [3].

Alternatively, non-economic incentives, license plate control (LPC) policy in particular, is adopted by the policy-maker. Basically, LPC policy places a cap on the total quantity of new license plates each year. Those license plates are further allocated between EV and GV applicants, respectively. On the basis of this policy, Beijing government employs a queueing up system in order to distribute purchasing 
permits to EV applicants directly, whereas the GV applicants need to compete for the permits within lottery system organized on $26^{\text {th }}$ every two months by Beijing Municipal Commission of Transport. Each lottery winner receives a nontransferable certification to purchase a vehicle [7]. Annual license plates allocation results of Beijing during recent years are shown in Fig.1.

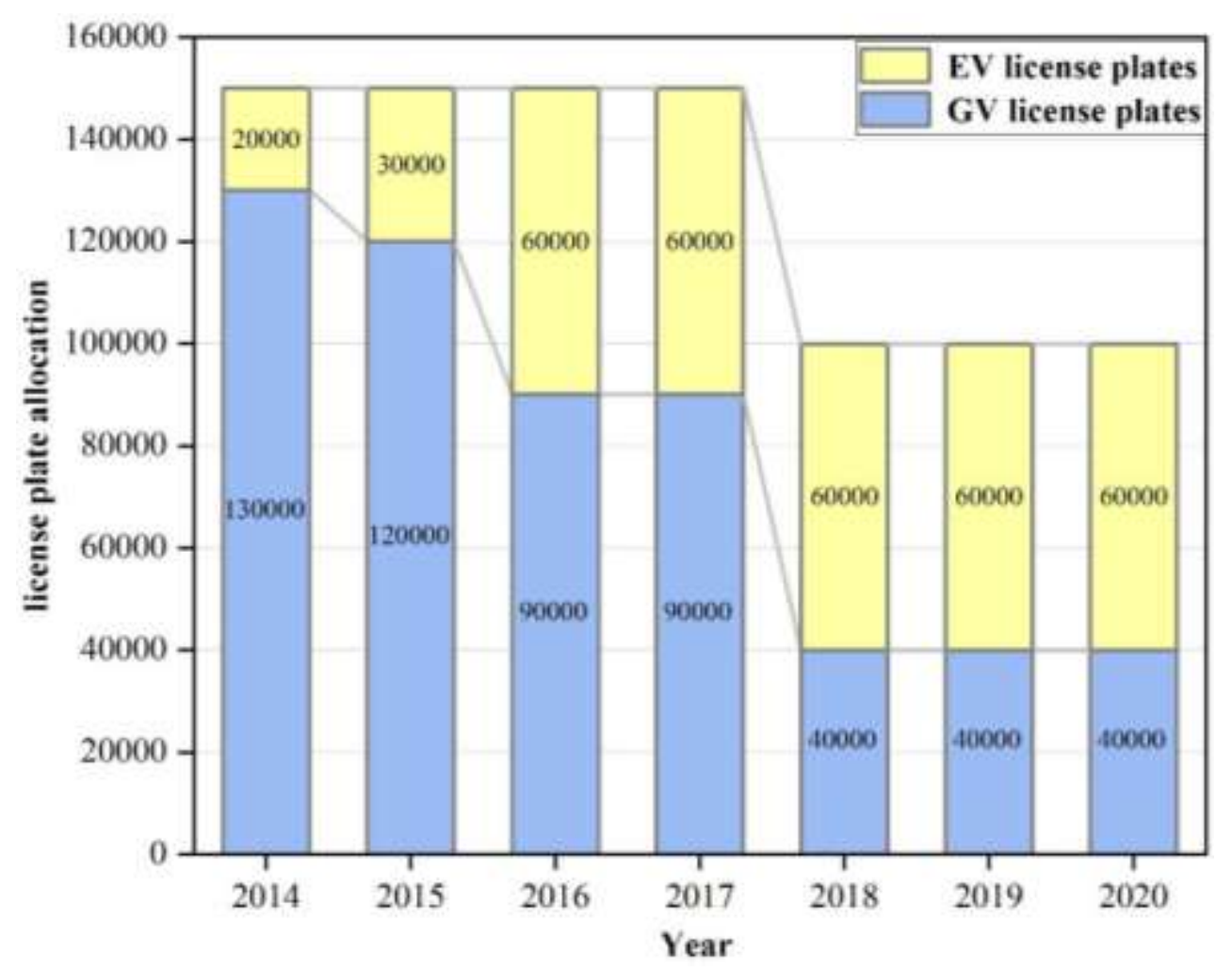

Fig. 1. Results of license plate allocation in Beijing from 2014 to 2020

Source: calculated by the authors according to data from The People's Government of Beijing Municipality

In 2019, according to the statistical result of The People's Government of Beijing Municipality ${ }^{1}$, over $3350500 \mathrm{GV}$ applicants registered on the website, while the annual quota of GV license plate was 40000. Probability of winning a GV license plate is $0.2 \%$ approximately, which implies that individual applicant needs to spend almost 41 years winning a GV license plate, whereas it would take each EV

\footnotetext{
${ }^{1}$ The People's Government of Beijing Municipality: Official website of the Beijing government which offers information on living in Beijing as well as other practical information.
} 
applicant about 9 years to obtain a EV license plate within the queueing up system. Some applicants tend to choose EVs so that they can get vehicles as soon as possible and that improves EV adoption significantly. License plate allocation policy influences the purchasing decision of applicants, which further impacts the social utility with consideration of applicant's utility and environment impact. Nevertheless, given an annual aggregate quota, how to allocate license plates between EVs and GVs so as to maximize social utility has not been analyzed among the current studies.

This paper fills the literature gap by proposing a game theory model to identify the optimal license plate allocation between EVs and GVs under the LPC policy in Beijing. The impact of license plate allocation on EV adoption is also analyzed. Main contributions of this study are as follows: Firstly, the optimal EV license plates under the LPC policy is theoretically studied for the first time. Secondly, sensitive analysis is conducted to analyze how the LPC policy affect EV penetration. Thirdly, the impact of key influential factors on EV penetration is discussed and corresponding implications are provided for the policy-maker.

The rest of paper is organized as follows: In section 2, the related literature is reviewed. In section 3, we propose a Stackelberg model between the government and applicants then prove the existence of equilibrium results. In section 4 , the practical equilibrium results are obtained by applying actual value of parameters. In section 5, we discuss the results and provide implications in order to improve EV adoption.

\section{Literature review}

\subsection{Policies for improving EV adoption}


Various policies have been implemented so far in order to improve EV penetration. ([7][8][9][10]). Among them, subsidy policies are widely mentioned and discussed. Jenn et al. [11] proposed three distinct generalized models so as to evaluate the effect of economic incentives on EV adoption and demonstrated that every $\$ 1000$ rebate would promote the sales of EV by $2.6 \%$. Similarly, using a large random sample of individuals, Sheldon et al. [12] demonstrated that if the subsidy had reduced by $50 \%$ due to the phasing out subsidy policy in China, the EV market share would have declined by $21 \%$.

Although subsidy has been regarded as an effective approach to improve EV diffusion, certain flaws cannot be ignored either: Firstly, subsidy policy could only increase the competitiveness of EV in a short run. In the long run, government tends to reduce the scale of subsidy to alleviate financial burden as EV adopters increases, which weakens the EV competitiveness consequently [3]. Ma et al. [13] illustrated that technology was a bottleneck factor for EV adoption and technology progress was much more influential than subsidy. Jang et al. [14] claimed that policy treating EV and GV technologies in a fair manner might be better than applicant-oriented subsidy policy. Secondly, implementation of subsidy policy is comparatively complicated. Once the incentive policy was conducted improperly, it would interrupt the vehicle market or even cause a backfire to it [15]. Having witnessed the fluctuation of Sweden EV market in 2014 when EV market share in Sweden declined from 2.1\% in August to less than $1.0 \%$ in November because of the rebate shortage, Tietge [16] implied that subsidy might result in unexpected damage to the EV improvement under extreme circumstance.

Apart from subsidy policies, certain non-economic policies have also been implemented during these years. Certificate of entitlement (COE) system, a sort of auction mechanism to manage vehicle ownership [17], was initiated by Singapore for the first time in 1992. Vehicle applicants were required 
to attend this system and bid for the certificates which allowed the applicants to drive on roads for 10 years [18]. The system turned out to be effective, since it led to a reduction of the vehicle annual growth rate in Singapore in 1990s (from 6.8\% to3\%). In China, a similar auction policy was implemented in Shanghai in 1994. After that, Beijing proposed a novel LPC policy in 2010 which regulated the license plate allocation of EVs and GVs by means of lottery systems [19]. Then in October 2015, Beijing government cancelled the EV license plate lottery and introduced a queueing system to EV applicants so as to improve EV diffusion. Lottery system, on the other hand, remains necessary for applying a GV license plate certificate [20]. This paper would mainly study Beijing's LPC policies, including queueing system as well as lottery system.

Generally, LPC policies includes auction and lottery ([3][7][20]). Two reasons that lottery mechanism is preferred by Beijing government are illustrated by Yang et al. [7]: Firstly, compared with the auction system invited by Singapore and followed by Shanghai ([7][21]), lottery mechanism is more fair for all citizens. Without any special requirement, applicants can register on the government website for free. Secondly, having distributed the residential houses with a lottery system successfully, Beijing government is expected to apply a similar lottery system in vehicle market. Until now, several studies have focused on the lottery mechanism implemented in Beijing. Yang et al. [7] analyzed the short term effect of lottery policy on Beijing's traffic situation and found that the congestion was alleviated significantly with lottery policy. Likewise, Yang et al. [22] estimated that lottery mechanism could reduce daily vehicle kilometers travelled and usage of cars in rush hour by $15 \%$ and $10 \%$ respectively. By conducting survey on 332 respondents, Zhang et al. [20] assessed the influence of lottery policy on EV adoption and suggested that lottery policy was more suitable and powerful to promote EVs in Beijing. 
Zhuge et al. [3] proposed an agent-based model and asserted that not only did the lottery policy in Beijing influence the EV adoption, but it also reduced the energy consumption and emission of vehicle.

The previous literature mainly focused on the current LPC policy's influence on the traffic, energy consumption and EV promotion. While the detailed license plates allocation under the LPC policy has been considered as an exogenous variable. However, It is noteworthy that the current license plates allocation may not be optimal from a social welfare maximization perspective. Therefore, this paper aims to analyze the optimal EV license plates under the LPC policy in Beijing.

\subsection{Models for evaluating EV incentives}

Certain methodologies have been utilized to evaluate the effectiveness of EV incentives, such as discrete choice model [23], regression model ([24][25]), agent-based model ([3][26][27]), multi-layer perspective model ([28][29]), and game theory model ([14][30][31]). A discrete choice model involving 247 respondents was employed by Wang et al. [23] to compare the effectiveness of several policies. The result showed that LPC policies implemented in certain Chinese cities had significantly positive impact on EV penetration. After operating a multiple linear regression, Wang et al. [32] found that direct subsidy scheme could not account for the different EV penetration levels among countries. An agentbased model was introduced by Noori and Tarari [26] to predict the development trajectories of several types of EV under the vehicle market uncertainty. Silvia et al. [27] established an agent-based model which simulated and compared four distinct policies with the benchmark. Similarly, Zhuge et al. [3] proposed an agent-based spatial integrated model named SelfSim-EV and then investigated how incentives impacted individual purchasing behaviors. The result suggested that purchasing permit policy could significantly influence on EV penetration. 
Apart from the methods mentioned above, Stackelberg game theory is prevalent in energy domain [33], such as electricity ([34][35]), renewable energy[36], and EV industries ([14][30][37][38]). It is commonly proposed to model the hierarchical interactions where stakeholders possess distinct objectives and the decisions made by different players exert mutual impact. In order to improve the effectiveness of government interference on vehicle market, a trilateral game model incorporating the government, vehicle manufactures, and vehicle applicants was employed by Qin et al. [30]. A sequential game was introduced by Yu et al. [38] to model the interaction between charging infrastructure investors and EV applicants. Zhu et al. [37] proposed a three-level Stackelberg game portraying the interaction among electricity supplier, charging infrastructure operator, and crowd-funders. Besides, a stylized Stackelberg game among vehicle manufacturers, applicants, and energy suppliers was depicted by Jang et al. [14] so as to identify policy implications for improving EV diffusion.

Under the LPC policy, the government decides vehicle license plates allocation and applicants decide to purchase EVs or GVs. The decisions of the players depend on each other's action. Given this hierarchical interaction, a two-level Stackelberg game model is proposed in this paper so as to quantify the players' optimal decisions under the LPC policy.

\section{Methodology}

\subsection{Stackelberg game model}

We consider two players in vehicle market under the LPC policy: the government and vehicle applicants. The government regulates specific license plates distribution between EV and GV then carries it out. Given fixed distribution, each applicant needs to consider whether purchasing EV or GV to maximize his/her own utility. For analytical tractability, we assume that vehicle applicants are 
homogenous and rational. The interaction between these two participants is portrayed in the diagram below.

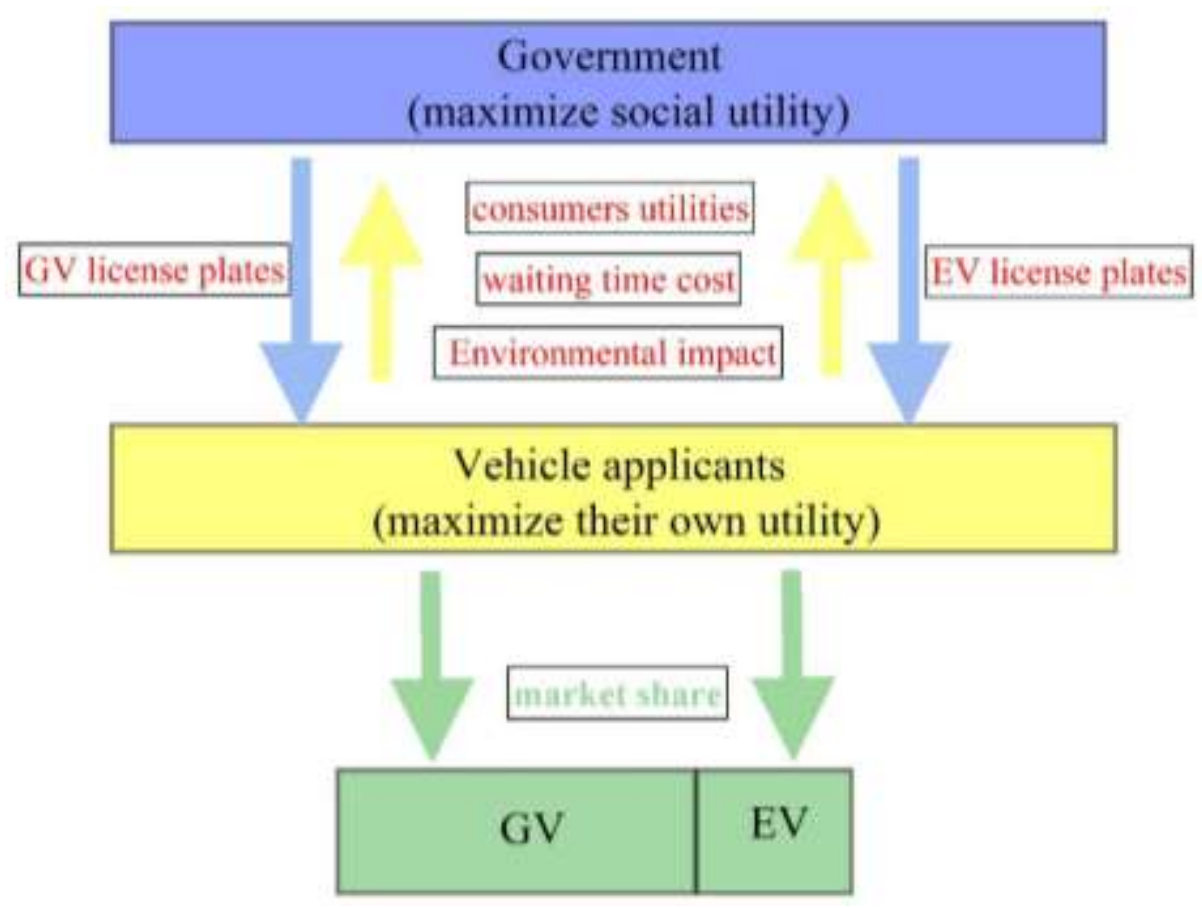

Fig.2. Interaction between the government and vehicle applicants

Stackelberg game model is introduced to depict the interaction between the government and vehicle applicants. Commonly, a Stackelberg game framework is established to depict the hierarchical interaction among participants where the leader has sufficient power over followers. In the game framework, a strategy is determined by leader firstly to maximize its utility, then the followers response sequentially based on the leader's strategy [39]. In this case, the government could be regarded as leader, while the applicants act as followers. The optimal license plate distribution obtained within this system depends on each participant's behavior: As for the vehicle applicants, the allocation between EV and GV license plates regulated by the government influences their utilities directly, impelling them to choose between EVs and GVs. Reversely, aggregate applicants' utilities, waiting time cost, and 
environmental impact caused by the applicants' purchasing choices contribute to the social welfare and influence the government's decision process.

\subsection{Decision model of applicant}

Discrete choice models have been used widely to model the vehicle purchasing decisions of applicants. This study applies a model to measure the probability of choosing a specific type of vehicle under certain attributes. Commonly, attributes including individual characteristics ([40][41][42]), government incentives ([43][44]), and charging or refueling infrastructures quantities ([45][46]) are considered to influence purchaser's behavior. Correspondingly, the utility functions shown in Eqs. (1) and (2) are formulated as the weighted sum of attributes incorporating vehicle prices, number of charging/refueling stations, car tail number restriction, and possibility of obtaining a license plate.

$$
\begin{gathered}
U_{G V}=\beta 1 * P_{G}+\beta 2 * I_{G}+\beta 3 * M_{G}+\beta 4 *\left(\left(N_{G} / 6\right) / B_{G}\right)+\varepsilon_{G} \\
U_{E V}=\beta 1 * P_{E}+\beta 2 * I_{E}+\beta 4 *\left(K-N_{G}\right) / B_{E}+\varepsilon_{E}
\end{gathered}
$$

Where $P_{G}, P_{E}$ are the average prices of GV and $\mathrm{EV}$ respectively; $I_{G}, I_{E}$ refer to the number of refueling stations as well as charging piles in Beijing; $M_{G}$ measures the probability of undergoing tail number restriction in weekdays for each gasoline vehicle; $N_{G}$ represents the quantity of GV license plates, since there are six lotteries operated by Beijing government each year, the quantity of EV license plates allocated in a given lottery should be one six of the annual quota $\left(\boldsymbol{N}_{\boldsymbol{G}} / \mathbf{6}\right) ; B_{E}$ denotes the number of EV applicants, whereas $B_{G}$ denotes the number of $\mathrm{GV}$ applicants; $K$ is the total license plates quota.

$\beta 1, \beta 2, \beta 3$, and $\beta 4$ are parameters describing applicants' sensitivities towards influential factors mentioned above. $\beta 1$ measures applicant's sensitivity to vehicle prices; $\beta 2$ measures the sensitivity to 
infrastructure quantity; $\beta 3$ measures the sensitivity to the probability of undergoing tail number restriction in weekdays; $\beta 4$ refers to the sensitivity to the probability of obtaining a license plate. On the basis of binary logit model, the possibility that individual applicant chooses whether EV or GV could be respectively defined as:

$$
\begin{gathered}
P_{E V}=\frac{e^{U_{E V}}}{e^{U_{E V}+e^{U_{G V}}}} \\
P_{G V}=\frac{e^{U_{G V}}}{e^{U_{E V}+e^{U_{G V}}}}
\end{gathered}
$$

Where $P_{E V}+P_{G V}=1$. After modifying Eqs. (3) and (4), a new regression equation is established as:

$\ln \left(\boldsymbol{P}_{E V} /\left(\mathbf{1}-\boldsymbol{P}_{E V}\right)\right)=\boldsymbol{\beta}_{1} *\left(\boldsymbol{P}_{E}-\boldsymbol{P}_{G}\right)+\boldsymbol{\beta}_{2} *\left(I_{E}-I_{G}\right)-\boldsymbol{\beta}_{3} * M_{G}+\boldsymbol{\beta}_{4} *\left(\left(K-N_{G}\right) / B_{E}-\left(N_{G} / 6\right) / B_{G}\right)(5)$

To estimate the values of four sensitivity parameters $(\beta 1, \beta 2, \beta 3$, and $\beta 4)$, this paper incorporates a survey conducted on Wenjuanxing, a prevalent online software in China mainland for academic research and data collection. The whole survey lasts from March to May in 2020. Each respondent is required to complete a questionnaire during the survey (Sample of the questionnaire is shown in Appendix C). Specifically, the questionnaire comprises two parts: the demographic information in the first part involves gender, age, education level, household income, and family member. The second part measures the respondent's sensitivities towards various factors which include vehicle prices, infrastructure quantity, possibility of undergoing tail number restriction, and probability of obtaining a license plate.

During the survey, 225 questionnaires were collected and 23 questionnaires were invalid because of missing data. (The demographic data of subjects is also shown in Appendix C). Then a binary logistic model is implemented to measure the sensitivity coefficients. On the basis of Eq. (5), we record the 
respondent who chose to purchase $\mathrm{EV}$ as 1 , whereas the one who chose to purchase GV as 0 . By inserting the data from 202 samples into the regression model, the results are shown in Table.1.

\begin{tabular}{lll}
\hline & $\beta$ & Sig. \\
\hline Vehicle price & -0.32 & 0.051 \\
Infrastructure quantity & 0.13 & 0.011 \\
Probability of undergoing tail number restriction & -0.11 & 0.22 \\
Probability of obtaining a license plate & 0.44 & 0.06 \\
Constant & -1.295 & 0.42 \\
-2 Log likelihood & 64.073 & \\
Cox \& Snell R & \\
Nagelkerke's R & 0.505 & \\
& 0.686 & \\
\hline
\end{tabular}

Tabel.1. The results of logistic regression

As it is shown in Table. 1 , four sensitive coefficients $\left(\beta_{1}, \beta_{2}, \beta_{3}\right.$, and $\left.\beta_{4}\right)$ involved in the regression are estimated. Besides, $\varepsilon_{G}$ and $\varepsilon_{E}$ are random variables referring to the unquantified attributes of applicants. Based on the studies of Yu et al. [38] and Zhu et al. [31], we assume that the random variables are subjected to the uniform distribution $\mathrm{u}(0,1)$. Both $\varepsilon_{G}$ and $\varepsilon_{E}$ vary from 0 to 1 and the relationship between them is:

$$
\varepsilon_{G}+\varepsilon_{E}=1
$$

For individual applicant, the following decision-making mechanism should be adopted so as to maximize his or her own utility:

$$
U_{\text {applicant }}=\operatorname{Max}\left(U_{G}, U_{E}\right)
$$

When $0<\eta<\eta^{*}, U_{\text {applicant }}=\operatorname{Max}\left(U_{G}, U_{E}\right)=U_{G}$, applicant chooses GV;

When $1>\eta>\eta^{*}, U_{\text {applicant }}=\operatorname{Max}\left(U_{G}, U_{E}\right)=U_{E}$, applicant chooses EV;

Where $\eta^{*}$ is the threshold value. Theoretically, when $\eta=\eta^{*}$, purchasing either GV or EV brings the 
same utility to applicant. The diagram below shows the specific mechanism of individual purchasing decision-making process:

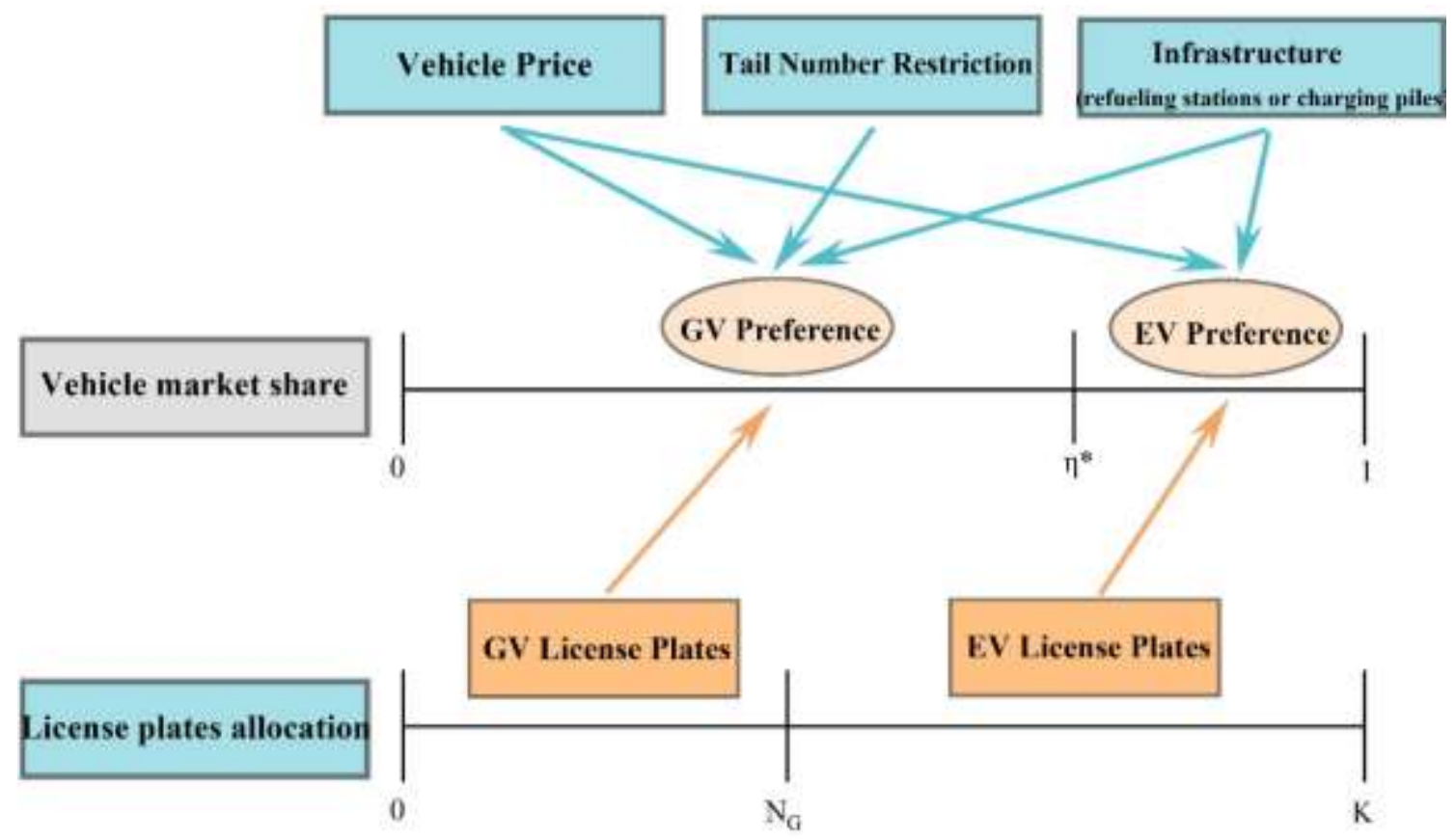

Figure.3. Diagram of purchasing decision-making process

Considering the decision-making process described above and Eq.(1),(2),(6),(7), the threshold value $\eta^{*}$ could be expressed as:

$$
\eta^{*}=\frac{\left(\beta 1 * P_{G}+\beta 2 * I_{G}+\beta 3 * M_{G}+1-\beta 1 * P_{E}-\beta 2 * I_{E}-\beta 4 *\left(K / B_{E}\right)+\beta 4 *\left(1 / B_{G}+1 / B_{E}\right) * N_{G}\right)}{2}
$$

\section{(Proof. See Appendix A)}

Consequently, the utility function for individual applicant could be expressed as:

$$
\begin{gathered}
U_{\text {applicant }}=\int_{0}^{\eta^{*}}\left(\beta 1 * P_{G}+\beta 2 * I_{G}+\beta 3 * M_{G}+\beta 4 *\left(N_{G} / 6\right) / B_{G}+\varepsilon_{G}\right) d \varepsilon_{E}+ \\
\int_{\eta^{*}}^{1}\left(\beta 1 * P_{E}+\beta 2 * I_{E}+\beta 4 *\left(K-N_{G}\right) / B_{E}+\varepsilon_{E}\right) d \varepsilon_{E}
\end{gathered}
$$




\subsection{Waiting time cost}

Waiting time cost is the expense of applicants who fail to obtain license plates as the result of the LPC policy. This paper adopts the assumption proposed by Hou et al. [46] that these applicants tend to rent vehicles to obtain similar commuting experience. Rental expense during waiting time is regarded as the implementation cost of LPC policy, influencing social welfare inevitably. Consequently, as a significant factor, waiting time cost should be considered by the government when regulating license plates allocation.

Currently, EV and GV license plates distribution mechanisms are totally different in Beijing. GV license plates are distributed within a public lottery system, whereas queueing up system is applied for EV applicants. In the following part, the expected waiting time of EV and GV applicants are formulated respectively.

\subsubsection{Expected waiting time of GV applicants}

For GV applicants, the winning probability would definitely determine their waiting time. To calculate the waiting time of GV applicants, an innovative duration model proposed by Hou et al. [47] is employed in this paper. By incorporating the hazard function, this model identifies the relationship between the winning probability and the expected waiting time of GV applicants, which is depicted as below: (Proof. See Appendix B)

$$
E\left(T_{G}\right)=\left[\int_{0}^{\infty} t * p *(1-p)^{t} * e^{\left(p *\left[1-\frac{(1-p) t}{\ln (1-p)}\right]\right)} d t\right] / 6
$$

Where $\mathrm{p}$ is the winning probability for GV applicants. Given the fact that Beijing government organizes six lotteries each year, when the annual quantity of GV license plates distributed is $\mathrm{N}_{\mathrm{G}}$ and that of $\mathrm{GV}$ 
applicants is $\mathrm{B}_{\mathrm{G}}$, the winning probability in a given lottery, $\mathrm{p}$, should be equal to $\left(\frac{\mathrm{N}_{\mathrm{G}}}{6}\right) / \mathrm{B}_{\mathrm{G}}$.

Based on the equation above, waiting time of GV applicant under different winning probabilities could be simulated.

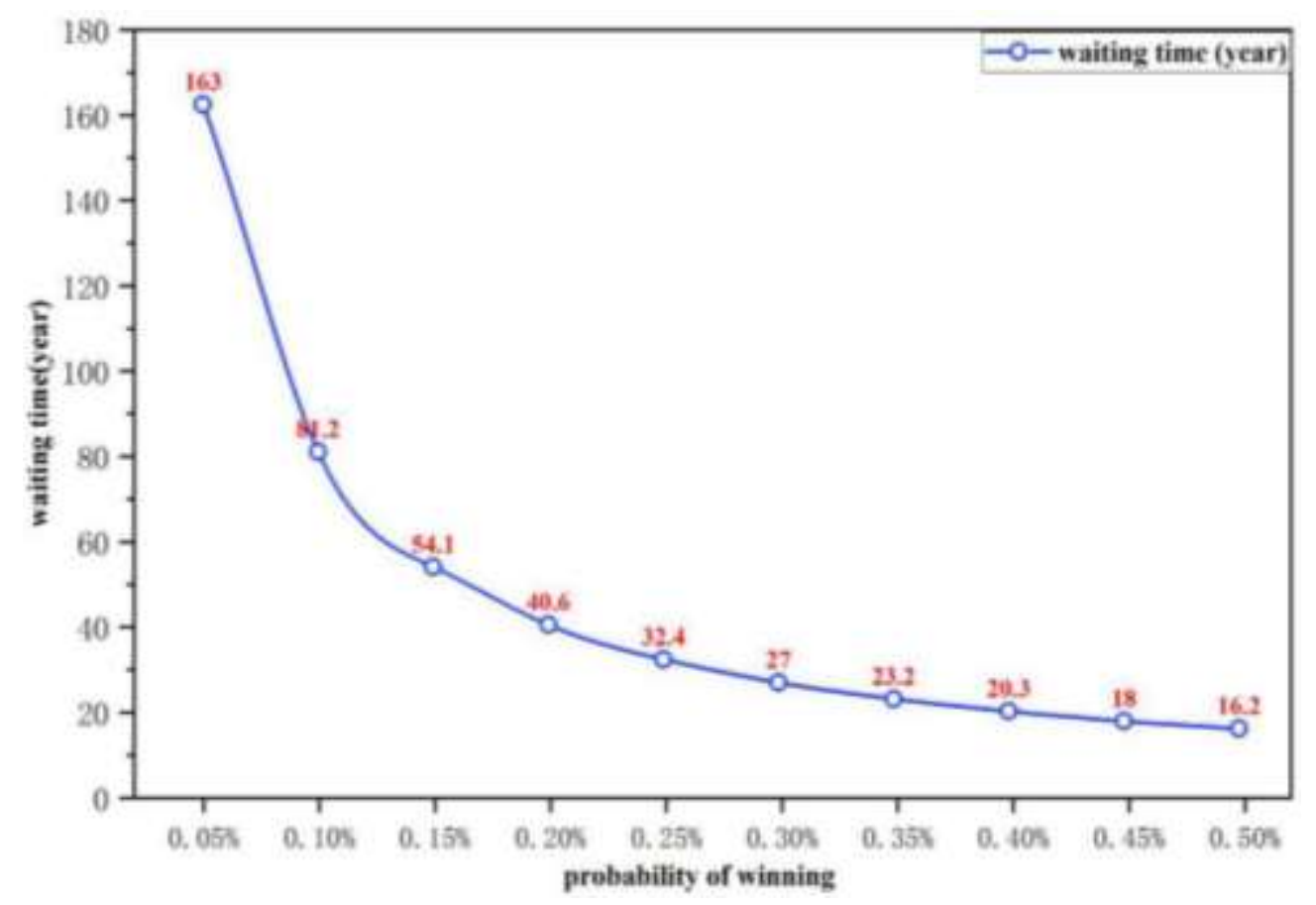

Figure.4. Waiting time of individual GV applicant under different winning probabilities.

In $2020, \mathrm{GV}$ license plates quota is 40000 , indicating that the current possibility of winning a GV license plate in each lottery is only $0.2 \%^{2}$. By referring to Figure. 4 , we could predict that it would approximately take an individual 41 years to win a GV license plate under current winning probability.

\subsubsection{Expected queue time of EV applicants}

Compared with the GV license plate lottery system, a queueing up system is applied to allocate EV license plates. Since the number of applicants within queueing up system is $B_{E}$ and that the annual EV

\footnotetext{
${ }^{2}$ In this scenario where annual GV license plates quota and applicants are 40000 and 3350500 respectively, the corresponding winning probability in a given lottery would be: $(40000 / 6) / 3350500=0.2 \%$.
} 
license plate quantity is $\left(K-N_{G}\right)$, we can deduce the formula of individual expected queue time.

$$
\mathbf{E}\left(\boldsymbol{T}_{E}\right)=\boldsymbol{B}_{E} /\left(\boldsymbol{K}-\boldsymbol{N}_{G}\right)
$$

Compared with the expected waiting time of GV applicants, the current queue time of each EV applicant, on average, is approximately only 7.79 years. The aggregated waiting time cost of both GV and EV applicants can be expressed as:

$$
\left\{\left[\int_{0}^{\infty} t * p *(1-p)^{t} * e^{\left(p *\left[1-\frac{(1-p)^{t}}{\ln (1-p)}\right]\right)} d t\right] / 6+B_{E} /\left(K-N_{G}\right)\right\} * \frac{1}{2} * 12 * C * K
$$

Where $\mathrm{c}$ is the vehicle rental fee per month.

\subsection{Environmental impact}

Environmental impact stands for the influence on environment brought by the vehicles to be distributed within a given year. In fact, it is comparatively complicated to quantify the environmental impact of exhaust gas emitted by these vehicles directly. As a consequence, energy consumption cost is measured as an alternative to indirectly portray environmental impact. To be specific, the cost of energy consumption refers to the expense paid by applicants for daily usage of gasoline and electricity during a given year. With respect to vehicle energy consumption, Kong et al. [48] has estimated that the average electricity consumption of EV is $17 \mathrm{kWh}$ per 100 kilometers, whereas the average gasoline consumption level of GV is 8 liters per 100 kilometers. Consequently, considering that there are approximately 360 days in a given year, annual energy consumption cost could be formulated as below:

$$
\left[N_{G} * D V K T * 8 / 100 * P_{g}+\left(K-N_{G}\right) * D V K T * 17 / 100 * P_{e}\right] * 360
$$


Where $D V K T^{3}$ is the average vehicle commuting distance in Beijing estimated by Hou et al. [49], $P_{g}$ and $P_{e}$ are gasoline price and electricity price.

\subsection{Decision model of government}

The government aims to maximize social welfare, including the aggregate utilities of vehicle applicants, the waiting time cost caused by LPC policy, and cost of energy consumed by EVs and GVs distributed in a given year. Among these three factors, the term aggregate utility of vehicle applicants is the gain of welfare, whereas the waiting time cost and energy consumption are considered as the welfare loss. Correspondingly, social welfare function can be formulated as below:

$$
\begin{aligned}
& \pi_{\text {social }}=\lambda_{1} *\left(\mathrm{U}_{\text {applicants }}\right)-\lambda_{2} *(\text { waiting time cost })-\lambda_{3} *(\text { energy consumption cost }) \\
& =\lambda_{1} *\left(\int_{0}^{\eta^{*}}\left(\beta 1 * P_{G}+\beta 2 * I_{G}+\beta 3 * M_{G}+\beta 4 *\left(\left(N_{G} / 6\right) / B_{G}\right)+\varepsilon_{G}\right) d \varepsilon_{E}+\int_{\eta^{*}}^{1}\left(\beta 1 * P_{E}+\beta 2 * I_{E}+\right.\right. \\
& \left.\left.\beta 4 *\left(K-N_{G}\right) / B_{E}+\varepsilon_{E}\right) d \varepsilon_{E}\right)-\lambda_{2} *\left(\left\{\left[\int_{0}^{\infty} t * p *(1-p)^{t} * e^{\left(p *\left[1-\frac{(1-p) t}{\ln (1-p)}\right]\right)} \mathrm{dt}\right] * \frac{1}{6}+\frac{B_{E}}{\left(K-N_{G}\right)^{2}}\right\} * \frac{1}{2} * 12 * C *\right. \\
& K)-\lambda_{3} *\left(N_{G} * D V K T * 365 / 100 * 8 * P_{g}+\left(K-N_{G}\right) * D V K T * 365 / 100 * 17 * P_{e}\right)
\end{aligned}
$$

Where coefficients $\lambda_{i}(i=1,2,3)$ are integrated into the welfare function in order to measure the gain and loss of the welfare.

\subsection{Stackelberg equilibrium results}

Due to the complexity of Eq. (14), it is impractical to derive the closed form solution by solving the first and second derivatives. Therefore, alternative approach should be adopted to prove the existence of the optimal value. Mathematica ${ }^{4}$ could be utilized to provide information on the property of a given

\footnotetext{
${ }^{3}$ As the abbreviation of "Daily Vehicle Kilometers Travelled", DVKT measures the average commuting distance of vehicles in Beijing.

${ }^{4}$ As a sort of mathematical software application, Mathematica comprises thousands of powerful functions for numeric and graphical computation.
} 
function, and in this case we introduce a commonly used graphics function of it, $\mathrm{Plot}^{5}$, which plots the graph of a function over a prescribed range, to portray marginal change in social welfare caused by $N_{G}$ (where: $0<N_{G}<100000$ ) in Fig. 5 .

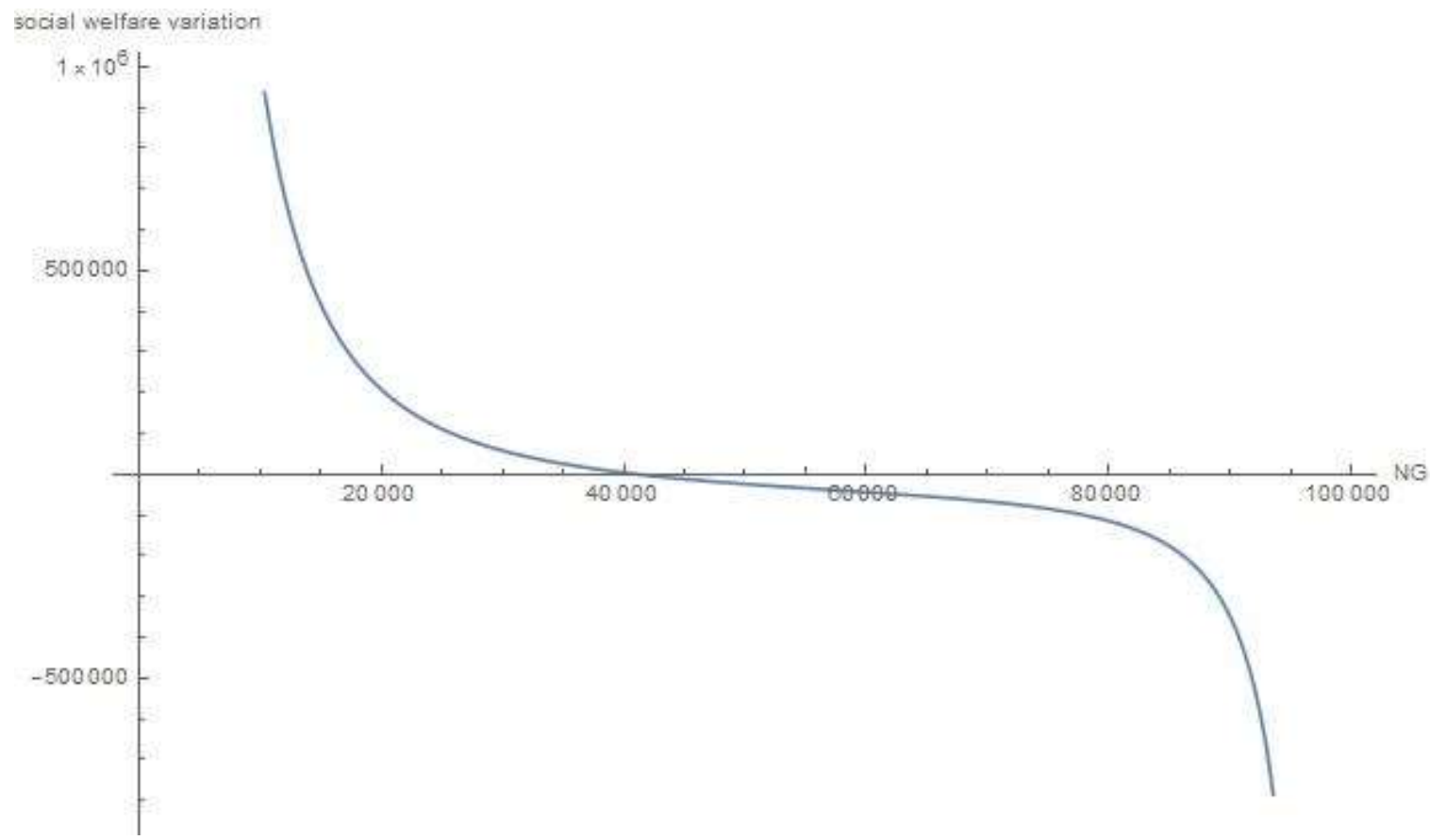

Figure.5. Marginal change in social welfare

The monotonic decreasing marginal change function and the existence of root in Figure. 5 indicate the existence of closed form solution $\left(N_{G}^{*}\right)$. Nevertheless, we could only obtain the approximate numerical solution by means of Mathematica. After substituting the approximate solution $N_{G}^{*}$ into Eq. (8), we derive the GV and EV market shares correspondingly.

\section{Estimation of parameters}

\footnotetext{
${ }^{5}$ The basic format of plotting is Plot [function, \{variable, lower bound, upper bound\}, Options]. In this paper, social welfare is the function we plan to depict, $N_{G}$ serves as a variable, and the lower bound is 0 , whereas the upper bound is $K(\mathrm{~K}=100000$ in benchmark level $)$.
} 
Estimations of the key parameters incorporated this study are shown as below:

\begin{tabular}{llll}
\hline Parameter & Estimated value & Parameter & Estimated value \\
\hline$\lambda 1$ & 1 & $P_{E}$ & $15^{*} 10^{4}$ \\
$\lambda 2$ & 0.046 & $P_{G}$ & $10^{*} 10^{4}$ \\
$\lambda 3$ & 10 & $I_{E}$ & $6.1^{*} 10^{4}$ \\
$\beta 1$ & -0.32 & $I_{G}$ & $0.904 * 10^{4}$ \\
$\beta 2$ & 0.13 & $M_{G}$ & 0.2 \\
$\beta 3$ & -0.11 & $K$ & 100000 \\
$\beta 4$ & 0.44 & $P_{e}$ & 0.6 \\
$B_{E}$ & 467400 & $P_{g}$ & 5.31 \\
$B_{G}$ & 3350500 & $C$ & 2377 \\
$D V K T$ & 46.35 & & \\
\hline
\end{tabular}

Table.2. The estimation of key parameters

According to the announcement of The People's Government of Beijing Municipality [50], total license plates quota, $K$, has been 100000 since 2018. The number of applicants who are willing to purchase EVs, $B_{E}$, is 467400 , whereas that of $\mathrm{GVs}, B_{G}$, is 3350500 . Besides, each GV in Beijing would be prohibited for one day in weekdays, which means that $M_{G}$ equals to 0.2 . The sensitivity indexes within applicant's utility function are obtained: $\beta 1=-0.32, \beta 2=0.13, \beta 3=-0.11, \beta 4=0.44$.

Approximately, the average price of electric vehicle $P_{E}$ and gasoline vehicle $P_{G}$ are $150000 \mathrm{CNY}$ and $100000 \mathrm{CNY}$, according to the quotations of private cars in Pacific Automative Network [51]. Moreover, the average cost of renting a vehicle, $c$, is estimated as $2377 \mathrm{CNY}$ per month [47]. Based on the statistical data derived from China Electric Vehicle Charging Infrastructure Promotion Alliance [52], almost 61000 public charging piles have been installed in Beijing, which indicates that $I_{E}$ equals to 61000 . Besides, there are 2260 gas stations in Beijing. We assume that each gas station is equipped with four refueling machines, which means that the aggregate quantity of refueling machines, $I_{G}$, is 9040. Furthermore, derived from the statistical data of The State Council of the People's Republic Of 
China [53], the average electricity price $P_{e}$ and gasoline price $P_{g}$ are $0.6 \mathrm{CNY}$ per kWh and 5.31 CNY per liter, respectively.

\section{Result analysis and discussions}

After applying the practical values of parameters into the Eq. (14), this paper obtains the equilibrium results: In 2020, the optimal GV license plates quantity, $N_{G}$, is 41200 , whereas the optimal EV license plates quantity is 58800 , which could increase the social welfare by $0.38 \%$. In other words, our model has proved that the current license plate allocation policy in Beijing is feasible considering social welfare.

To provide managerial insights for policy-maker, some influential factors and their effects on vehicle market are discussed in this part.

\subsection{The impact of the total quota on license plate allocation and EV diffusion}

From 2014 to 2018, the annual license plates quota was 150000 . Nevertheless, it has reduced to 100000 since 2018 so as to satisfy the emission reduction need proposed by the central government. However, recently certain cities in China decides to restore local vehicle markets which are suffered from COVID 19 by enlarging annual license plates quota. For example, Beijing plans to add extra 20000 license plates and Guangzhou also decides to assign 10000 license plates to the applicants.

Therefore, it is necessary to analyze how the optimal EV license plates allocation varies with the increased total quota. 


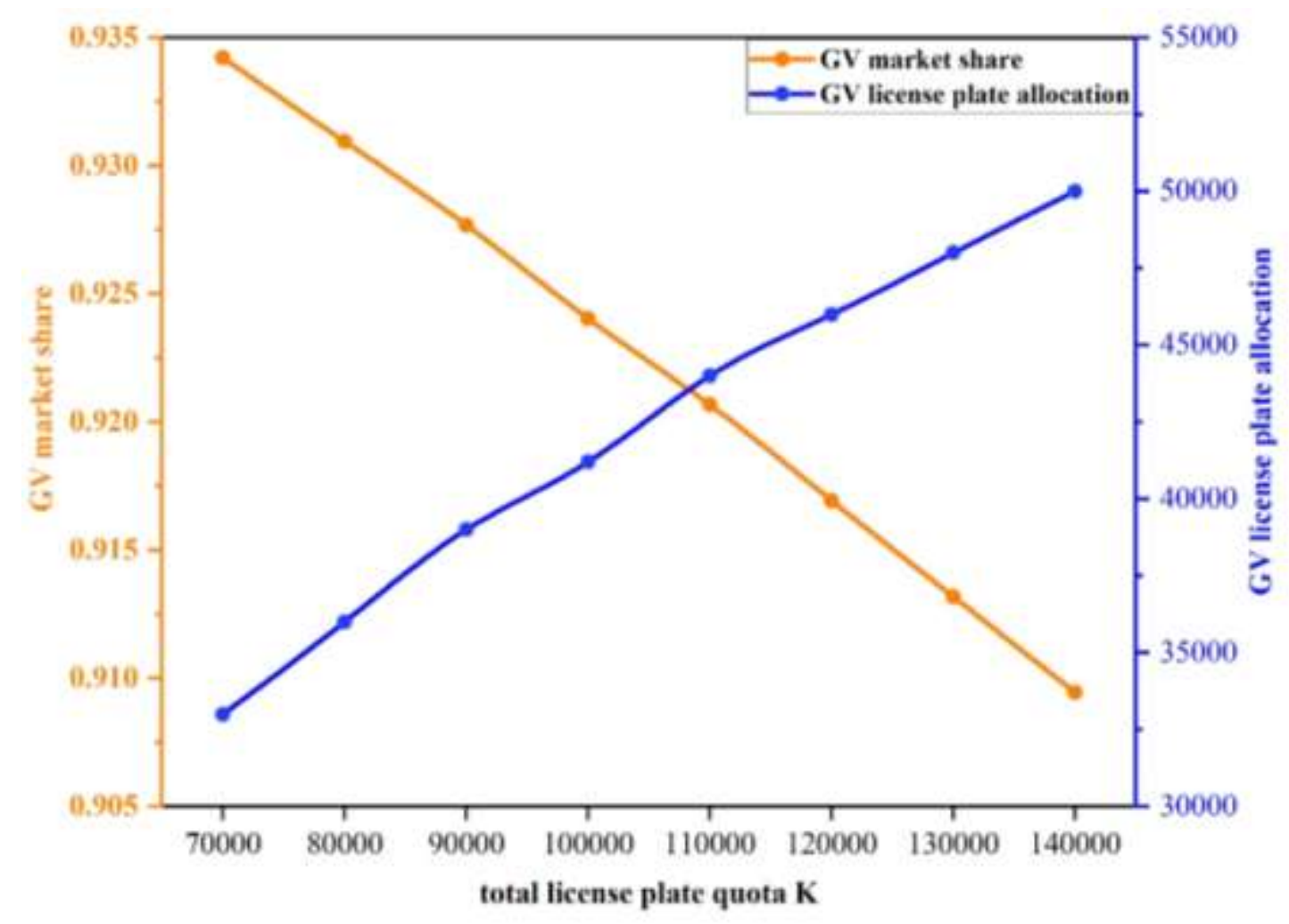

Fig.6. The influence of total quota on GV market share and allocation.

As it is shown in Fig.6, when the government enlarges total quota up to 120000, the optimal GV license plates quantity increases from 41200 to 46000 , and that of EV license plates varies from 58800 to 74000 . In other words, if the government enlarges total quota up to $120000,24 \%$ should be added to $\mathrm{GV}$, and $76 \%$ should be allocated to $\mathrm{EV}$. The increment in total quota will contribute to the promotion of EV diffusion by rise its market share from $7.6 \%$ to $9.18 \%$.

\subsection{The impact of vehicle rental fee on license plate allocation and EV diffusion}

Each year, plenty of applicants fail to obtain license plates due to the LPC policy in Beijing and this paper holds the assumption proposed by Hou et al. [47] that they tend to rent vehicles alternatively to achieve similar experience as those who have owned vehicles. Therefore, the rental expense they afford 
is considered as the implementary cost of the LPC policy. Given the fact that total rental expense would influence social welfare inevitably, the role that vehicle rental fee plays on license plate allocation and EV diffusion should be explored.

In order to simulate the influence of rental fee on EV diffusion, two rental fee levels are considered: the benchmark rental fee (C1) is $2377 \mathrm{CNY} /$ month and an approximate $33 \%$ reduction of the benchmark (C2), is $1577 \mathrm{CNY} /$ month. Based on the calculation results from the Eq. (9), the market share of EV would increase from $7.6 \%$ to $7.9 \%$. The result is intriguing since it suggests that the government could improve EV penetration by reducing the rental fee. In order to figure out the mechanism behind this result, we compare the rental expenses of individual applicant under two different rental fees in Fig. 7. 


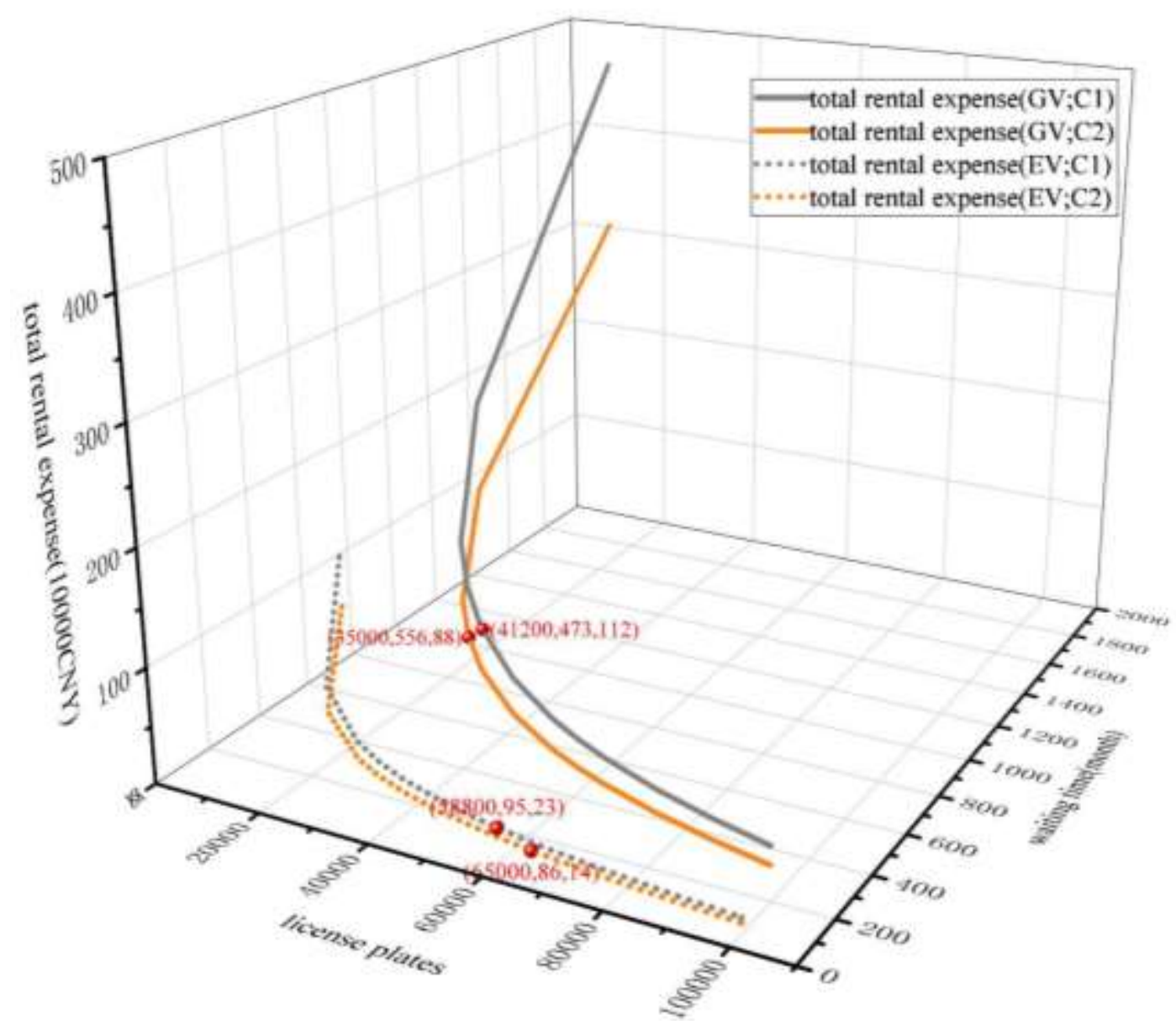

Fig.7. License plate allocations and rental expenses under different rental fees

As it is shown in Fig. 7, when the current rental fee reduces from $2377 \mathrm{CNY} /$ month to 1577 CNY/month, the quantity of optimal EV license plates would increase by $10.5 \%$, from 58800 to 65000 . On the basis of Eq. (11), the waiting time of EV applicant would decline by $9.5 \%$, from 95 months to 86 months. Consequently, the individual rental expense would decrease from $225815 \mathrm{CNY}$ to 135622 CNY, suggesting a $40 \%$ saving. The lower rental fee, in contrast, would lead to a reduction of GV license plates (from 41200 to 35000) and hence a much longer waiting time for GV applicant (from 473 months to 556 months). But it also brings a significant saving to GV applicants, since the rental expense would drop from $1124321 \mathrm{CNY}$ to $876812 \mathrm{CNY}$. 
In other words, a lower rental fee would be helpful to improve EV diffusion, because it leads to more EV license plates, less waiting time and rental expense. As for the GV applicants, the reduction of rental expense brings less financial burden to them.

Consequently, certain measurements to stimulate the growth of Beijing's vehicle rental industry [55] and to reduce the vehicle rental fee should be considered by the policy-maker. First, under the current phasing-out EV subsidy policy in China, more subsidies should be transferred from EV purchasing to vehicle rental industry. Second, regulations should be issued by policy-maker to improve transparency of the rental market and efficiency of the official supervision, so that the average rental price could be maintained in a low level.

\subsection{The impact of energy prices on license plate allocation and EV diffusion}

Gasoline price and electricity price affect customers' preferences to GV and EV, and hence are considered as key factors for EV diffusion. This section aims to explore managerial insights for the government in term of different energy prices. As shown in Fig. 8 , three electricity prices $(0.4 \mathrm{CNY} / \mathrm{kWh}$, 0.6 $\mathrm{CNY} / \mathrm{kWh}$, and $0.8 \mathrm{CNY} / \mathrm{kWh}$ ) are proposed and gasoline price varies from $3 \mathrm{CNY} /$ liter to 10 CNY/liter. 


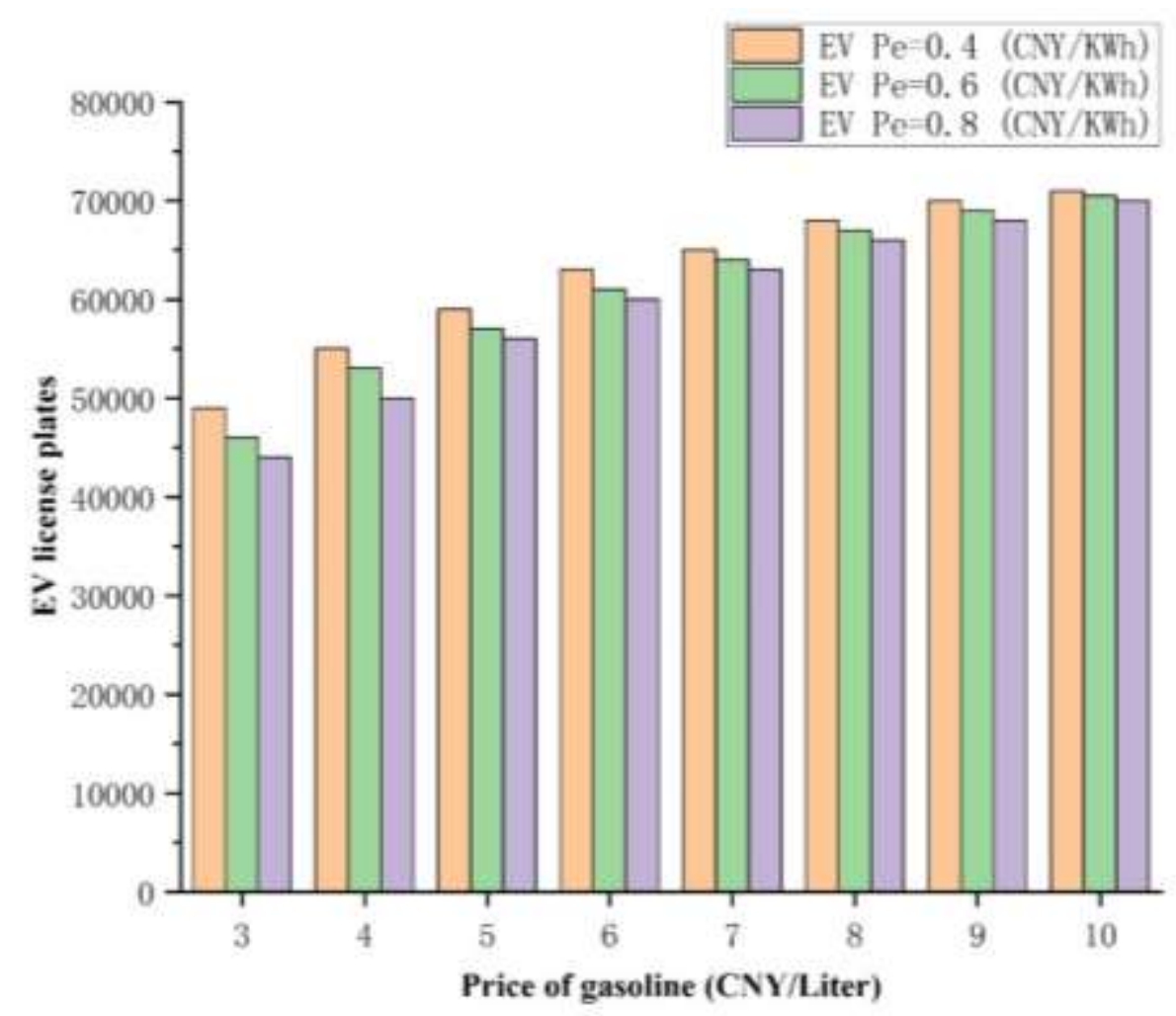

Fig.8. Impact of electricity price on EV penetration under different gasoline prices.

It is found that the quantity of EV license plate goes up with an increasing gasoline price. In contrast, it goes down with an increasing electricity price. It is noteworthy that the changing rate of EV license plate contracts when gasoline price increases. In more detail, given a relatively low gasoline price level ( 3 or $4 \mathrm{CNY/liter} \mathrm{for} \mathrm{instance),} \mathrm{gap} \mathrm{in} \mathrm{EV} \mathrm{license} \mathrm{plates} \mathrm{(between} \mathrm{the} \mathrm{highest} \mathrm{and} \mathrm{lowest} \mathrm{electricity} \mathrm{price}$ scenarios) is 5000 approximately; when the gasoline price is higher ( 9 or $10 \mathrm{CNY} /$ liter), that gap almost disappears. In the latter situation, the cost of electricity consumed by EV is much less than that of gasoline consumed by GV when covering the same distance. Therefore, most applicants would be less sensitive to the electricity price and choose EV without any hesitation, therefore more EV license plates should be provided by the government.

For example, given the current gasoline price in China (around 5.31 CNY/liter), the quantity of EV license plates would rise by $3.5 \%$ when the government reduces the electricity price from the current 
0.6 CNY/kWh to $0.4 \mathrm{CNY} / \mathrm{kWh}$, which suggests a significant effect caused by electricity price reduction on EV diffusion. It implies that the government could promote EV diffusion effectively by reducing electricity price when the gasoline price is low.

By comparison, when the gasoline price increase to around $7 \mathrm{CNY} /$ liter, by reducing the electricity price in the same way, the EV market share expands by only $1.5 \%$, indicating that reducing electricity price would be less effective in improving EV diffusion when the gasoline price is high. In this situation, to increase the competitiveness of $\mathrm{EV}$, more attention should be focused on reducing the production cost of EVs, such as the cost of EV battery [54] or engine.

\section{Conclusion and policy implication}

This study quantified EV adoption in Beijing under the LPC policy and identified the optimal license plate allocation between EVs and GVs. A two-level Stackelberg game was proposed to model the interaction between vehicle applicants and the government. The results indicate some implications for policy-making.

(1) From a social welfare maximization perspective, under the current total license plates quota (100000), the optimal EV license plate quantity is modelled to be 58800. Under COVID-19, if the Beijing government additionally adds 20,000 quota , $76 \%$ could be allocated to EV.

(2) Vehicle rental fee is found to be an important factor for EV diffusion. One third reduction of the current rental fee could increase EV license plates by $10.5 \%$, reduce the waiting time of EV applicants by $9.5 \%$, and save individual rental expense by almost $40 \%$. Consequently, policies aim to reduce rental fee could be considered. First, more subsidies might be redistributed from EV users 
to vehicle rental industry. Second, regulations might be issued by policy-makers to improve transparency of the rental market and efficiency of the official supervision.

(3) When gasoline price is comparatively low, vehicle applicants are more sensitive to electricity price variation. Consequently, it is more effective for the government to enlarge EV diffusion by reducing electricity price. At a higher gasoline price, however, the applicants would pay less attention on electricity price. Therefore, alternative measurements could be adopted by the government so as to improve EV competitiveness, such as reducing the production cost of EV battery or engine. 


\section{Appendices:}

\section{Appendix A}

\section{The threshold of GV market share}

For individual vehicle applicant, the utility functions of purchasing EV and GV are defined as:

$$
\begin{aligned}
& U_{G}=\beta 1 * P_{G}+\beta 2 * I_{G}+\beta 3 * M_{G}+\beta 4 * N_{G} /\left(6 * B_{G}\right)+\varepsilon_{G} \\
& U_{E}=\beta 1 * P_{E}+\beta 2 * I_{E}+\beta 4 *\left(K-N_{G}\right) / B_{E}+\varepsilon_{E}
\end{aligned}
$$

Considering the specific relationship between the random variables from Eq. (6), we substitute $\varepsilon_{\mathrm{G}}$ with $\varepsilon_{\mathrm{E}}$ into the following equation:

$\beta 1 * P_{G}+\beta 2 * I_{G}+\beta 3 * M_{G}+\beta 4 *\left(N_{G} / 6\right) / B_{G}+\varepsilon_{G}=\beta 1 * P_{E}+\beta 2 * I_{E}+\beta 4 *\left(K-N_{G}\right) / B_{E}+\varepsilon_{E}$ Eq. (A.1)

The algebra expression of $\eta^{*}$ is:

$$
\eta^{*}=\frac{\left(\beta 1 * P_{G}+\beta 2 * I_{G}+\beta 3 * M_{G}+1-\beta 1 * P_{E}-\beta 2 * I_{E}-\beta 4 *\left(\frac{K}{B_{E}}\right)+\beta 4 *\left(\frac{1}{B_{G}}+\frac{1}{B_{E}}\right) * N_{G}\right)}{2}
$$




\section{Appendix B}

\section{The duration model}

For individual GV applicant, the distribution function of the applicant's waiting time, $F(t)$, denotes the possibility of winning a license plate within $t$ term of lottery. $f(t)$ refers to the probability density function correspondingly. $\mathrm{S}(\mathrm{t})$ defined as the survival function measures the possibility that applicant fails to win a license plate within $\mathrm{t}$ terms of lotteries:

$$
S(t)=1-F(t)=P(T>t)
$$

The hazard function $K(t)$ denoting the possibility that applicant fails to win a license plate in $t$ terms of lotteries but win one within time interval $(\mathrm{t}, \mathrm{t}+\mathrm{h})$ is defined as:

$$
K(t)=\lim _{h \rightarrow 0} \frac{P(t \leq T \leq t+h \mid T \geq t)}{h}=\lim _{h \rightarrow 0} \frac{P(t \leq T \leq t+h)}{h * P(T \geq t)}=\lim _{h \rightarrow 0} \frac{F(t+h)-F(t)}{h * S(t)}=-\frac{\partial \ln S(t)}{\partial t}
$$

By modifying the equation, we obtain a first-order differential equation shown as below:

$$
\frac{d S(t)}{d t}+S(t) * K(t)=0
$$

$\mathrm{S}(\mathrm{t})$ could be derived by solving the equation Eq. (B.3):

$$
S(t)=\int\left(K(t) * e^{-\int_{0}^{t} K(m) d m}\right) d t
$$

Correspondingly, the probability density function could be obtained:

$$
f(t)=K(t) * e^{-\int_{0}^{t} K(m) d m}
$$

Based on the duration model, if the probability of winning a license plate in each lottery is $p$, the hazard function $\mathrm{K}(\mathrm{t})$ should be expressed as:

$$
K(t)=(\mathbf{1}-\boldsymbol{p})^{t} * \boldsymbol{p}
$$

By substituting Eq. (B.6) in Eq. (B.5), we could obtain the algebra expression of the possibility density 
function $f(t)$ :

$$
f(t)=(1-p)^{t} * p * e^{\frac{p *\left(1-(1-p)^{t}\right)}{\ln (1-p)}}
$$

Since there are 6 lotteries held in each year, the expected waiting time of GV applicant is:

$$
E\left(\boldsymbol{T}_{G}\right)=\left(\int_{0}^{+\infty} t * f(t) d t\right) * \frac{1}{6}=\left(\int_{0}^{+\infty} t *(1-p)^{t} * p * e^{\frac{p *(1-(1-p) t}{\ln (1-p)}} d t\right) * \frac{1}{6}
$$




\section{Appendix C}

\section{Questionnaire sample}

Q1: What gender do you identify as?

a. Male

b. Female

\section{Q2: What is your age?}
a. 25 and below
b. $26 \sim 35$
c. $36 \sim 45$
d. $46 \sim 55$
e. 56 and above

Q3: What is the highest degree or level of education you have completed? (If currently enrolled,

highest degree received).
a. Middle school degree and below
b. High middle school degree
c. Bachelor's or associate degree
d. Master's degree
e. Doctor's degree

Q4: What is your household income per month?
a. Under10000 CNY
b. $10001 \sim 20000 \mathrm{CNY}$
c. $20001 \sim 30000 \mathrm{CNY}$
d. $30001 \sim 40000 \mathrm{CNY}$
e. More than $40000 \mathrm{CNY}$

Q5: How many family members do you have?
a. 1
b. 2
c. 3
d. 4
e. 5 or more

Q6: Which type of vehicle do you plan to purchase?

a. Electric vehicle (Battery EV/ Hybrid EV/ Plug-in Hybrid EV/ Full Cell EV) 
b. Gasoline vehicle

Q7: What is the price of the vehicle that you plan to purchase?
a. Under $100000 \mathrm{CNY}$
b. $100001 \sim 150000 \mathrm{CNY}$
c. $150001 \sim 200000 \mathrm{CNY}$
d. 200001 250000 CNY
e. $250001 \sim 300000 \mathrm{CNY}$
f. 300001 400000 CNY
g. More than $400000 \mathrm{CNY}$

Q8: (If you plan to purchase a gasoline vehicle, please answer this question.) What is the price of electric vehicle that you think can bring similar driving experience?
a. Under $100000 \mathrm{CNY}$
b. $100001 \sim 150000 \mathrm{CNY}$
c. $150001 \sim 200000 \mathrm{CNY}$
d. $200001 \sim 250000 \mathrm{CNY}$
e. $250001 \sim 300000 \mathrm{CNY}$
f. 300001 400000 CNY
g. More than $400000 \mathrm{CNY}$

Q9: (If you plan to purchase an electric vehicle, please answer this question). What is the price of gasoline vehicle that you think can bring similar driving experience?
a. Under $100000 \mathrm{CNY}$
b. $100001 \sim 150000 \mathrm{CNY}$
c. $150001 \sim 200000 \mathrm{CNY}$
d. 200001 250000 CNY
e. 250001 300000 CNY
f. 300001 400000 CNY
g. More than $400000 \mathrm{CNY}$ 
Q10*: After obtaining a vehicle, how many days do you plan to drive out in weekdays?
a. 1
b. 2
c. 3
d. 4
e. 5

Q11*: What is the longest time you can wait to obtain a EV license plate in queueing system?
a. Less than 3 years
b. $3 \sim 5$ years
c. $6 \sim 8$ years
d. $9 \sim 11$ years
e. More than 12 years

Q12: How long do you think it takes to find a charging pile?
a. Less than $10 \mathrm{~min}$
b. $10 \sim 20 \mathrm{~min}$
c. $20 \sim 30 \mathrm{~min}$
d. $30 \sim 40 \mathrm{~min}$
e. More than $40 \mathrm{~min}$

Q13: How long do you think it takes to find a gas station?
a. Less than $10 \mathrm{~min}$
b. $10 \sim 20 \mathrm{~min}$
c. $20 \sim 30 \mathrm{~min}$
d. $30 \sim 40 \mathrm{~min}$
e. More than $40 \mathrm{~min}$ 
The table below depicts the demographic data of the survey:

\begin{tabular}{|c|c|c|}
\hline & Frequency & Percentage $(\%)$ \\
\hline \multicolumn{3}{|l|}{ Gender } \\
\hline Male & 105 & 51.98 \\
\hline Female & 97 & 48.02 \\
\hline Total & 202 & 100 \\
\hline \multicolumn{3}{|l|}{ Age } \\
\hline 25 and below & 38 & 18.81 \\
\hline $26-35$ & 103 & 50.99 \\
\hline $36-45$ & 41 & 20.30 \\
\hline $46-55$ & 16 & 7.92 \\
\hline 56 and above & 4 & 1.98 \\
\hline Total & 202 & 100 \\
\hline \multicolumn{3}{|l|}{ Educational level } \\
\hline Middle school degree and below & 8 & 3.96 \\
\hline High middle school degree & 15 & 7.43 \\
\hline Bachelor's or associate degree & 99 & 49.01 \\
\hline Master's degree & 57 & 28.21 \\
\hline Doctor's degree & 23 & 11.39 \\
\hline Total & 202 & 100 \\
\hline \multicolumn{3}{|l|}{ Family member } \\
\hline 1 & 15 & 7.43 \\
\hline 2 & 46 & 22.77 \\
\hline 3 & 69 & 33.16 \\
\hline 4 & 34 & 16.83 \\
\hline 5 and above & 38 & 18.81 \\
\hline Total & 202 & 100 \\
\hline \multicolumn{3}{|l|}{ Household income (CNY; Month) } \\
\hline Under 10000 & 50 & 24.75 \\
\hline $10001-20000$ & 76 & 37.62 \\
\hline 20001-30000 & 42 & 20.79 \\
\hline $30001-40000$ & 11 & 5.45 \\
\hline More than 40000 & 23 & 11.39 \\
\hline Total & 202 & 100 \\
\hline
\end{tabular}




\section{References:}

[1]. Pan, X., et al., Decarbonization of China's transportation sector: In light of national mitigation toward the Paris Agreement goals. Energy, 2018. 155: p. 853-864.

[2]. Yuan, X., X. Liu and J. Zuo, The development of new energy vehicles for a sustainable future: A review. Renewable and Sustainable Energy Reviews, 2015. 42: p. 298-305.

[3]. Zhuge, C., et al., The role of the license plate lottery policy in the adoption of Electric Vehicles: A case study of Beijing. Energy Policy, 2020. 139: p. 111328.

[4]. Gu, H., Z. Liu and Q. Qing, Optimal electric vehicle production strategy under subsidy and battery recycling. Energy Policy, 2017. 109: p. 579-589.

[5]. Li, Z. and M. Ouyang, The pricing of charging for electric vehicles in China-Dilemma and solution. Energy, 2011. 36(9): p. 5765-5778.

[6]. Xiao, X., Z. Chen and P. Nie, Analysis of two subsidies for EVs: Based on an expanded theoretical discrete-choice model. Energy, 2020. 208: p. 118375.

[7]. Yang, J., et al., A review of Beijing's vehicle registration lottery: Short-term effects on vehicle growth and fuel consumption. Energy Policy, 2014. 75: p. 157-166.

[8]. Zhang, X., Reference-dependent electric vehicle production strategy considering subsidies and consumer trade-offs. Energy Policy, 2014. 67: p. 422-430.

[9]. Helveston, J.P., et al., Will subsidies drive electric vehicle adoption? Measuring consumer preferences in the U.S. and China. Transportation Research Part A: Policy and Practice, 2015. 73: p. 96-112.

[10]. Zhu, L., P. Wang and Q. Zhang, Indirect network effects in China' s electric vehicle diffusion under phasing out subsidies. Applied Energy, 2019. 251: p. 113350.

[11]. Jenn, A., K. Springel and A.R. Gopal, Effectiveness of electric vehicle incentives in the United States. Energy Policy, 2018. 119: p. 349-356.

[12]. Sheldon, T.L. and R. Dua, Effectiveness of China's plug-in electric vehicle subsidy. Energy Economics, 2020. 88: p. 104773.

[13]. Ma, S., Y. Fan and L. Feng, An evaluation of government incentives for new energy vehicles in China focusing on vehicle purchasing restrictions. Energy Policy, 2017. 110: p. 609-618.

[14]. Jang, D., B. Kim and S. Lee, A two-sided market platform analysis for the electric vehicle adoption: Firm strategies and policy design. Transportation Research Part D: Transport and Environment, 2018. 62: p. 646-658.

[15]. Gneezy, U., S. Meier and P. Rey-Biel, When and Why Incentives (Don't) Work to Modify Behavior. Journal of Economic Perspectives, 2011. 25(4): p. 191-210.

[16]. Tietge, U., Lessons learned from Sweden's electric vehicle rollercoaster. The international Council on Clean Transportation, 2017.

[17]. Chu, S., Car restraint policies and mileage in Singapore. Transportation Research Part A: Policy and Practice, 2015. 77: p. 404-412.

[18]. Han, S.S., Managing motorization in sustainable transport planning: the Singapore experience. Journal of Transport Geography, 2010. 18(2): p. 314-321.

[19]. Wang, S. and J. Zhao, The distributional effects of lotteries and auctions - License plate regulations in Guangzhou. Transportation Research Part A: Policy and Practice, 2017. 106: p. 473-483.

[20]. Zhang, X., X. Bai and H. Zhong, Electric vehicle adoption in license plate-controlled big cities: Evidence from Beijing. Journal of Cleaner Production, 2018. 202: p. 191-196. 
[21]. Chen, X. and J. Zhao, Bidding to drive: Car license auction policy in Shanghai and its public acceptance. Transport Policy, 2013. 27: p. 39-52.

[22]. Yang, J., et al., The effect of vehicle ownership restrictions on travel behavior: Evidence from the Beijing license plate lottery. Journal of Environmental Economics and Management, 2020. 99: p. 102269.

[23]. Wang, N., L. Tang and H. Pan, Effectiveness of policy incentives on electric vehicle acceptance in China: A discrete choice analysis. Transportation Research Part A: Policy and Practice, 2017. 105: p. 210-218.

[24]. Clinton, B., et al., Impact of Direct Financial Incentives in the Emerging Battery Electric Vehicle Market: A Preliminary Analysis. 2015.

[25]. Mersky, A.C., et al., Effectiveness of incentives on electric vehicle adoption in Norway. Transportation Research Part D: Transport and Environment, 2016. 46: p. 56-68.

[26]. Noori, M. and O. Tatari, Development of an agent-based model for regional market penetration projections of electric vehicles in the United States. Energy, 2016. 96: p. 215-230.

[27]. Silvia, C. and R.M. Krause, Assessing the impact of policy interventions on the adoption of plug-in electric vehicles: An agent-based model. Energy Policy, 2016. 96: p. 105-118.

[28]. Djalante, R. and S. Djalante, Derk Loorbach: Transition management, new mode of governance for sustainable development. Natural Hazards, 2012. 62(3): p. 1339-1341.

[29]. Figenbaum, E., Perspectives on Norway' s supercharged electric vehicle policy. Environmental innovation and societal transitions, 2017. 25: p. 14-34.

[30]. Qin, Z. and G. Zhu, A marketing Analysis of Electric Vehicles Based on Trilateral Game among Government, Enterprises and Consumers. Industrial Engineering Journal, 2015. 18(04): p. 1-8+42.

[31]. Zhu, L., P. Wang and Q. Zhang, Indirect network effects in China's electric vehicle diffusion under phasing out subsidies. Applied Energy, 2019. 251: p. 113350.

[32]. Wang, N., L. Tang and H. Pan, A global comparison and assessment of incentive policy on electric vehicle promotion. Sustainable Cities and Society, 2019. 44: p. 597-603.

[33]. Lu, Q., S. Lü and Y. Leng, A Nash-Stackelberg game approach in regional energy market considering users' integrated demand response. Energy, 2019. 175: p. 456-470.

[34]. Wang, C., et al., Risk assessment of integrated electricity and heat system with independent energy operators based on Stackelberg game. Energy, 2020. 198: p. 117349.

[35]. Zhang, X., et al., Deep transfer Q-learning with virtual leader-follower for supply-demand Stackelberg game of smart grid. Energy, 2017. 133: p. 348-365.

[36]. Sun, J., J. Lin and Y. Qian, Game-theoretic analysis of competitive agri-biomass supply chain. Journal of Cleaner Production, 2013. 43: p. 174-181.

[37]. Zhu, L., et al., Study on crowdfunding' s promoting effect on the expansion of electric vehicle charging piles based on game theory analysis. Applied Energy, 2017. 196: p. 238-248.

[38]. Yu, Z., S. Li and L. Tong, Market dynamics and indirect network effects in electric vehicle diffusion. Transportation Research Part D: Transport and Environment, 2016. 47: p. 336-356.

[39]. Zhang, X., et al., Deep transfer Q-learning with virtual leader-follower for supply-demand Stackelberg game of smart grid. Energy, 2017. 133: p. 348-365.

[40]. He, X., W. Zhan and Y. Hu, Consumer purchase intention of electric vehicles in China: The roles of perception and personality. Journal of Cleaner Production, 2018. 204: p. 1060-1069.

[41]. Ouyang, D., Q. Zhang and X. Ou, Review of Market Surveys on Consumer Behavior of Purchasing and Using Electric Vehicle in China. Energy Procedia, 2018. 152: p. 612-617. 
[42]. Chu, W., et al., Psychological and behavioral factors affecting electric vehicle adoption and satisfaction: A comparative study of early adopters in China and Korea. Transportation Research Part D: Transport and Environment, 2019. 76: p. 1-18.

[43]. Diamond, D., The impact of government incentives for hybrid-electric vehicles: Evidence from US states. Energy Policy, 2009. 37(3): p. 972-983.

[44]. Lin, B. and W. Wu, Why people want to buy electric vehicle: An empirical study in first-tier cities of China. Energy Policy, 2018. 112: p. 233-241.

[45]. Javid, R.J. and A. Nejat, A comprehensive model of regional electric vehicle adoption and penetration. Transport Policy, 2017. 54: p. 30-42.

[46]. Egnér, F. and L. Trosvik, Electric vehicle adoption in Sweden and the impact of local policy instruments. Energy Policy, 2018. 121: p. 584-596.

[47]. Hou, X., S. Peng and Y. Ma, Cost Analysis of and Comparison between Beijing's Car Plate Lottery and Shanghai's License Auction. China soft science magazine, 2013(11): p. 58-65.

[48]. Kong, W., Q. Li and X. Wang, Analysis on Energy Saving and Emission Reduction of Electric Vehicles Based upon Life-Cycle Energy Efficiency. Electric Power, 2012. 45(9): p. 64-67.

[49]. Hou, C., H. Wang and M. Ouyang, Survey of daily vehicle travel distance and impact factors in Beijing. IFAC Proceedings Volumes, 2013. 46(21): p. 35-40.

[50]. The People's Government of Beijing Municipality, Beijing Municipal Passenger Car Index Regulation Management Information System.. 2020.

[51]. Pacific Automotive Network, Quotation of small vehicle. 2020.

[52]. China Electric Vehicle Charging Infrastructure Promotion Alliance. 2020.

[53]. The State Council of the People's Republic Of China, China raises gasoline, diesel retail prices. 2020.

[54]. Ajanovic, A., The future of electric vehicles: prospects and impediments. Wiley interdisciplinary reviews. Energy and environment, 2015. 4(6): p. 521-536.

[55]. Fan, J., J. Wang and X. Zhang, An innovative subsidy model for promoting the sharing of Electric Vehicles in China: A pricing decisions analysis. Energy, 2020. 201: p. 117557. 


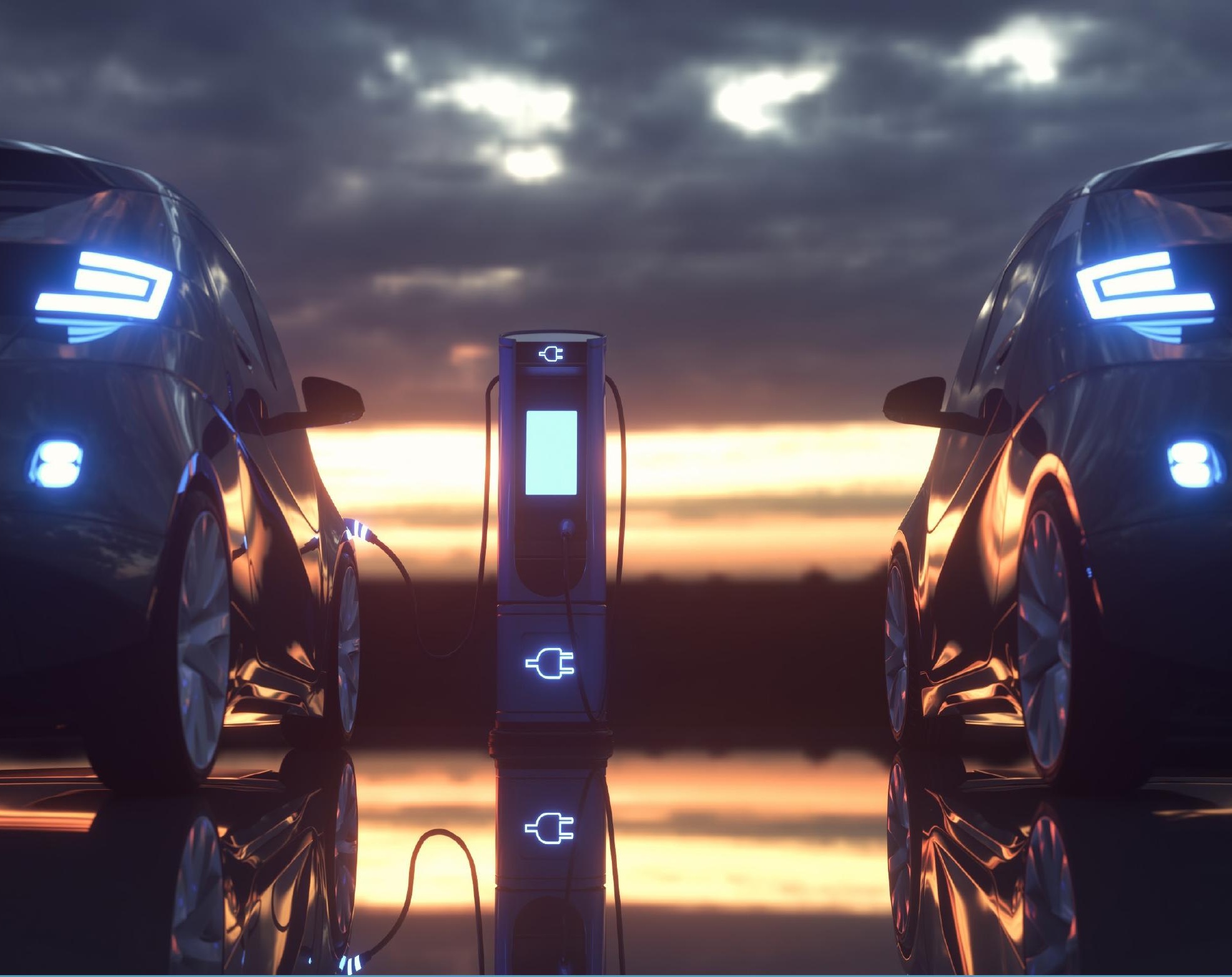

Retrouvez toute la collection

https://www.ifpenergiesnouvelles.fr/article/les-cahiers-leconomie

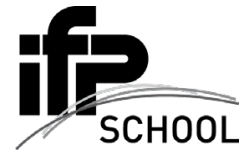

228 - 232 avenue Napoléon Bonaparte

92852 Rueil-Malmaison

www.ifpschool.com

\section{(ifP energers}

1-4 avenue de Bois-Préau

92852 Rueil-Malmaison

www.ifpenergiesnouvelles.fr 